\title{
ACERCA DE LA FUNCIÓN DE LAS ESCALAS PENALES, LAS CONSECUENCIAS DE UNA CONTRADICCIÓN NORMATIVA Y LA RESPONSABILIDAD EN VIRTUD DE LA ACTIO ILLICITA IN CAUSA
}

\section{INTRODUCCIÓN}

El trabajo de Alonso acerca de "normas penales y conflicto de deberes" trata el problema del sujeto que se encuentra, en principio, ante dos alternativas de conducta igualmente antinormativas, sin que exista una tercera posibilidad. El análisis se realiza desde diversas perspectivas. En los puntos 1 a 4 desgrana el asunto desde un punto de vista lógico y iusfilosófico sobre el que no me encuentro en condiciones de hacer ningún aporte. En el punto 5, una vez establecido con precisión en qué consiste este caso especial de conflicto de deberes, Alonso analiza, ya desde una perspectiva jurídico-dogmática,

* CONICET, Argentina qué es lo que se sigue, en cuanto a la 
delictuosidad, de las alternativas de conducta con las que cuenta el sujeto. Bajo los términos "condena o absolución" se propone determinar si las opciones en cuestión son delictivas o no, y en base a qué razón. En este único punto se centran mis observaciones.

En primer lugar, analizo el sub-punto 5.2. donde Alonso descarta que la respuesta a este conflicto normativo pueda encontrarse en las escalas penales previstas para cada delito. Sostengo allí lo contrario. Considero que los montos de pena establecidos por el legislador, por lo menos en este caso, pueden ser decisivos para dirimir la cuestión. Las afirmaciones de Alonso esconden alguna ambigüedad referente a la función de las escalas penales en particular y de las normas penales en general que trato de precisar en esta parte. Por último, aquí también explicito con base a qué elemento de la teoría del delito se puede dar cuenta de esta solución (infra 2).

En segundo lugar, me detengo en la solución brindada por Alonso. Este análisis subsidiario se basa en que, independientemente de la plausibilidad de la propuesta anterior, considero desacertada (una de las posibles interpretaciones de) esta solución. Si por "nunca actuará antijurídicamente" se entiende que, haga lo que haga el sujeto, su conducta deberá considerarse justificada, se está defendiendo algo conceptualmente insostenible. Si realmente no se puede dirimir qué norma es la que prevalece, la solución no puede encontrarse en que la conducta no es antijurídica porque el sujeto siempre estará cumpliendo un deber. Pues para saber esto previamente hay que determinar qué norma prepondera (cuál es el deber) y esto es lo que, según Alonso, no se puede saber. Por el contrario, si el conflicto es irresoluble, estamos frente a una antinomia de la que se sigue, en un estado de Derecho, la ausencia de tipicidad por falta de lex certa (infra 3 ).

Finalmente, se plantea una tercera hipótesis de solución. Existe una salida distinta a la de la atipicidad válida aún considerando que las escalas penales no cuentan para solucionar este problema. Para que esto sea factible, empero, es necesario agregar un dato adicional que "merodea el caso", pero que no ha sido incluido en el análisis de Alonso: el conocimiento por parte del sujeto al momento de librar el cheque de que probablemente será declarado en quiebra antes de ser intimado al pago. Si el sujeto es conciente de esa circunstancia y de que, por ende, 
probablemente no podrá pagar el cheque sin infringir otro deber, puede ser sancionado penalmente con independencia de la conducta que realice, es decir, puede ser sancionado en ambos casos. En este supuesto, el sujeto es responsable por la situación conflictiva en la que se encuentra y por ello no puede aducir el conflicto como una circunstancia eximente. Para dar cuenta de esta posibilidad es necesario traer a colación la estructura de la actio illicita in causa con su correspondiente justificación (infra 4).

\section{LA FUNCIÓN DE LAS ESCALAS PENALES}

(a) En la doctrina penal no se discute que las escalas penales cumplen, al menos, una función de orientación para determinar el valor de los diversos bienes jurídicos. En la medida en que se amenaza con más pena al delito de homicidio que al de daño, puede concluirse, en principio, que la vida tiene más valor que la propiedad ${ }^{1}$. Se reconoce ampliamente que este no es el único factor que cuenta, pero también que es relevante, por lo menos como punto de partida. Frente a esta justificación de la relevancia de las escalas penales, Alonso se pronuncia en contra de la siguiente manera:

no puede afirmarse que 'no matar' es más importante que 'no dañar el patrimonio' porque el primero está penado más severamente que el segundo, sino lo contrario: porque la vida es más importante que el patrimonio es que 'matar' tiene mayor pena que 'dañar el patrimonio'?

Esta afirmación puede ser entendida tanto descriptiva como prescriptivamente. Si se la entiende como una descripción de lo que el legislador hace no habría aquí mayores inconvenientes para solucionar el conflicto. Justamente porque el patrimonio es más valioso que la fe

\footnotetext{
${ }^{1}$ En este sentido, Roxin, Derecho penal, parte general, t.I, Fundamentos, La estructura de la teoría del delito, 2da. ed., Civitas, Madrid, 1997, nm. 16/23.

${ }^{2}$ En 5.2.
} 
pública es que el fraude a la quiebra $(\mathrm{FQ})$ tiene una pena más elevada que la omisión de pago de cheque (OPC) y, por consiguiente, no habría dificultades en determinar cuál es el deber que se debe seguir. Sin embargo, de lo que sigue en el texto de Alonso se puede deducir que su afirmación tiene un carácter prescriptivo. La frase indica que el legislador debe basar la graduación de las escalas penales en el valor del bien jurídico. Lo que no está claro, no obstante, son las consecuencias de este mandato para la solución del caso.

Para que dicha prescripción se encuentre carente de problemas prácticos, y sea útil para la solución de nuestro caso, hay que suponer, entre otras cosas, un acuerdo general acerca de cuáles son todos los valores sociales. Y, además, que las previsiones legislativas son, en algún sentido, superfluas, pues o bien dan cuenta de ellos, y por tanto no haría falta norma alguna, o bien no lo hacen, y por ello deben ser dejadas de lado al momento de evaluar una conducta. Las normas tendrían así un mero carácter declarativo o serían inválidas. Trasladado a las escalas penales y al problema que nos aqueja, esto significa que o bien las escalas penales reflejan la importancia de los valores sociales y resuelven el problema debido a esa coincidencia o bien la solución debe ser hallada con independencia de ellas y, por ende, son irrelevantes. Esta segunda afirmación parece ser la que sostiene Alonso.

Pero una coincidencia semejante dista de reflejar el estado de la discusión acerca de las cuestiones morales en las sociedades occidentales actuales. En éstas existen desacuerdos sobre prácticamente cualquier cosa. Por eso, entre otras cosas, se han generado autoridades centralizadas, cuyas decisiones acerca de los conflictos sociales resulten vinculantes. Para que dicha autoridad sea legítima debe incorporar a la discusión acerca de las normas la mayor cantidad de puntos de vista posible. Por ello el parlamento elegido democráticamente es la mejor institución en este sentido. Pero, y justamente por la plurirepresentatividad de estos centros de discusión, de ningún modo puede asegurarse que todos los puntos de vista sean contemplados en la decisión final ${ }^{3}$. Habrá personas o grupos de personas que estarán de

\footnotetext{
${ }^{3}$ Cfr. Peralta, Prevención general positiva como respeto por el orden jurídico, Indret Penal, Barcelona, 2008, www.indret.com, p. 10 y ss., con numerosas referencias ulteriores.
} 
acuerdo con la decisión y otros que no. Para quienes hayan visto triunfar su postura en la discusión, la decisión legislativa será, en cierto sentido, redundante. Pero frente a los que no hayan logrado ese cometido la norma se transforma en una nueva razón para actuar, con independencia de sus propias creencias ${ }^{4}$.

En el ejemplo que opone propiedad frente a vida no se percibe demasiado la relevancia de esta distinción porque aquí existe, a grandes rasgos, una extensa coincidencia valorativa. Pero en la discusión acerca de la legitimidad de la prohibición del aborto, por ejemplo, las posiciones están claramente divididas y es allí donde puede percibirse la importancia de diferenciar entre lo que se cree correcto y lo que se debe hacer. Efectivamente, ese eventual desacuerdo valorativo no es óbice a que la norma que ha decidido la cuestión sea vinculante. Todo lo contrario, justamente allí es donde la norma adquiere mayor relevancia determinando qué se debe hacer al darle prevalencia a alguna de las posturas. Una vez que se ha arribado al resultado la norma general vincula a sus destinatarios porque así lo ha resuelto el legislador y no porque sea más grave en el sentido de que el destinatario de la norma coincida con esta decisión.

En el caso que nos ocupa esta distinción parece adquirir mayor relevancia debido a otro factor adicional. Aquí, a diferencia de lo que sucede, por ejemplo, en la discusión sobre el aborto, parece no poder hablarse de convicciones uniformes o divididas en la sociedad al respecto. Parece más bien que esto no tiene demasiada relevancia moral en general. No existe un debate público al respecto y si le preguntáramos a alguien qué vale más, si la fe pública o la propiedad, probablemente no pueda elaborar respuesta alguna al respecto. Y esto no hace más que traer agua al molino de la vinculatoriedad de la disposición legislativa. La decisión por darle prioridad a uno u otro de los bienes jurídicos parece asemejarse al carácter de las acciones mala quia prohibita, en donde una decisión, o la prioridad de una sobre otra, no refleja una valoración moral en ningún sentido, sino la necesidad de organizar la sociedad de algún modo 5 .

\footnotetext{
${ }^{4}$ Raz, en, el mismo, Ethics in the Public Domain, Clarenton Press, Oxford, 1994, 179, 190 s. también 194, 197.

${ }^{5}$ Como cuando se ordena "mantener la derecha" y no "la izquierda" en el tráfico rodado.
} 
Pero más allá de esta última disquisición, no se le quiere negar aquí relevancia a la necesidad de que el derecho deba reflejar una determinada escala de valores. La afirmación de Alonso tiene relevancia práctica, pero sólo en tanto y en cuanto se la entienda como un mandato al legislador. Este debe buscar reflejar la gravedad de los bienes jurídicos al momento de establecer las escalas penales ${ }^{6}$. Pero las escalas de valores que no hayan sido reconocidas por el legislador no valen como parámetro de conducta para cada individuo, que debe obrar en base a otras razones, en concreto, por lo decidido por la autoridad. Su coincidencia personal o no con esta decisión debe ser irrelevante. De lo contrario, si el derecho debiera dar cuenta a efectos prácticos (i.e. para determinar qué hacer ${ }^{7}$ ) de los puntos de vista de todos los individuos, debería desintegrarse conforme al pensamiento de cada uno de ellos para quienes debería regir una norma particular según lo que consideren correcto. $\mathrm{Y}$ así no habría ordenamiento jurídico alguno ${ }^{8}$.

En conclusión, para determinar si el sujeto debe pagar el cheque, y afectar el patrimonio común de los acreedores, o si debe no pagarlo, y afectar la fe pública, debe ser decidido conforme a las valoraciones generales, reflejadas en las escalas penales, y no conforme a lo que el destinatario de la norma considere más grave o importante.

(b) Es cierto, de todas maneras, que, como afirma Alonso citando a Roxin, el criterio del "valor del bien" no es el único que

\footnotetext{
${ }^{6}$ Por lo menos según algunas visiones del Derecho penal. Para quien ve en éste una función sin ninguna vinculación deontológica, las escalas penales pueden reflejar otras cosas, como la frecuencia en la comisión de los hechos o la sensibilidad social a los acontecimientos delictivos.

${ }^{7}$ Como dijimos, los diversos puntos de vista deben ser tenidos en cuenta al momento de la discusión sobre la generación de la norma, sólo que no al momento de evaluar la vinculatoriedad de la norma ya establecida.

${ }^{8}$ Existe aquí un problema con las normas que contradicen crasamente valores fundamentales completamente arraigados. Probablemente, nuestro ordenamiento positivo actual no las consideraría válidas, debido a las normas constitucionales actualmente vigentes. Pero no deja, igualmente, de ser un problema importante para la validez de un derecho positivo de estas características, que contingentemente hoy no existe. Pero, felizmente, esta dificultad no se plantea en el caso en cuestión.
} 
tiene importancia para determinar la intensidad de la pena. Además se

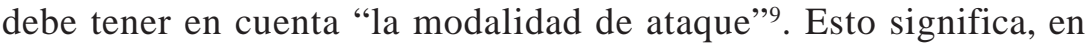
pocas palabras, que existen ciertos tipos penales que tienen contempladas escalas penales más elevadas que otros, no porque reflejen un bien jurídico de mayor valor, sino porque dan cuenta de una forma de ataque más intensa. Sin embargo, no parece que esto pueda debilitar la relevancia de las escalas penales como parámetro de decisión. Pues, definitivamente, las modalidades de ataque también son relevantes para determinar qué se debe hacer y, en este sentido, las escalas penales siguen siendo dirimentes.

Por ejemplo: si alguien en un estado de necesidad agresivo debe decidir, para llevar a su hijo al hospital, si debe sustraer un vehículo que tiene la puerta abierta y las llaves colocadas u otro, para cuyo acceso es necesario romper el vidrio y el tambor de arranque, debe resolver por el primer curso de acción ${ }^{10}$.

El deber de omisión de una conducta es tanto mayor en cuanto las modalidades de ataque sean más idóneas para lesionar el bien jurídico. Existe un deber superior de omitir conductas potencialmente más lesivas de bienes jurídicos que de omitir aquellas que lesionan menos ${ }^{11}$. Si esto es lo que señalan las escalas penales, con mayor razón deben ser seguidas.

En efecto, la relación entre tipo básico y tipo agravado, muchas veces, no pasa por la pluriofensividad de la acción (i.e. en que lesione más de un bien jurídico), sino porque el ataque al mismo bien es más intenso (i.e. en que lesiona más un bien jurídico). Así, la calificante del hurto por escalamiento (163 inc. $4 \mathrm{CP}$ ) puede estar justificada en que el sujeto además de hurtar comete el ilícito de violación de domicilio. Pero, por el contrario, el hurto calamitoso (163 inc. 2) sólo es más grave debido a la situación de especial vulnerabilidad en que se encuentra la

\footnotetext{
${ }^{9}$ Alonso, 5.2; Roxin (n.1) nm. 16/24 y 26; Jakobs, Strafrecht, Allgemeiner Teil, 2. ed. Die Grundlagen und die Zurechnungslehre, Berlin-New York, 1991, nm. 13/20; Stratenwerth/Kühlen, Strafrecht, Allgemeinter Teil I, 5ta. ed., Die Straftat, Heymanns, Köln, entre otras, 2004, nm. 9/105.

${ }^{10}$ De otro modo, habrá obrado con exceso intensivo en estado de necesidad. Este exige siempre optar por el medio menos lesivo disponible.

${ }^{11}$ Por todos, Stratenwerth/Kühlen (n.9), nm. 9/107 ss.
} 
víctima, que torna esa conducta más eficaz para lesionar el mismo bien jurídico.

Existe otra interpretación posible de la importancia de la modalidad de ataque que sí pone en jaque la relevancia de las escalas penales en abstracto y así la postura aquí defendida. La idea es la siguiente. Una cierta modalidad de acción concreta, por el peligro que implica, puede hacer que un hecho típico sea merecedor, dentro de una escala penal determinada, de una pena más cercana al máximo; mientras que otra forma de acción, por su falta de gravedad, puede transformar a otro hecho, aún subsumible dentro del mismo tipo y, con ello, sometible a la misma escala penal, en merecedor de una pena cercana al mínimo. Así, se podría incluso invertir el orden indicado prima facie por las escalas penales. Si bien, por ejemplo, se puede afirmar el valor integridad física tiene más peso que el de la propiedad, riesgos mínimos sobre la integridad pueden hacer que prevalezca el valor propiedad, si este último resulta expuesto a un gran riesgo. Quien, para evitar el incendio sobre su vivienda, conduce el auto violando las normas de tránsito y lesiona a un transeúnte, puede considerar su conducta justificada más allá de las penas establecidas para cada delito. En este sentido, se puede decir que, conforme a las modalidades de ataque a veces hay que dejar de lado las escalas penales.

Si esto es así, se podría pensar en que, en este caso, por la forma en que se realiza, el tipo de FQ es merecedor de una pena menor a la del máximo, y la forma de acción del hecho de OPC lo hace merecedor, en cambio, de una pena sí cercana al máximo de la escala penal correspondiente, de tal modo que, conforme las modalidades del caso concreto, ya las escalas en abstracto no puedan determinar la situación, supongamos, porque en ambos casos el autor debería padecer una pena de cuatro años.

Para sostener esto que, en rigor, no cuestiona en sí el valor de las escalas penales como tales, sino que precisa su operatividad conforme a cada caso ${ }^{12}$, deberían haberse proporcionado razones de por

\footnotetext{
${ }^{12}$ En efecto, conforme a las reglas de la mensuración de la pena (art. 41 inc. $2 \mathrm{CP}$ ) las modalidades de comisión del hecho son relevantes para determinar, dentro de un marco penal, qué pena corresponde imponer. Ex ante esto significa que las modalidades de acción también deben ser tenidas en cuenta para calcular las
} 
qué hay que abandonar el valor indiciario de las escalas penales consideradas en abstracto. Es decir, hubiera sido necesario justificar por qué, en este caso, la QF hubiera ameritado, por ejemplo, una pena media, y por qué la OPC hubiera ameritado, digamos, una pena máxima. Incluso los autores citados por Alonso entienden que las escalas penales pueden ser dejadas de lado si hay razones para ello. Esas razones no son proveídas por Alonso y son difíciles de imaginar. Por ello, a pesar de esta posibilidad, parece apropiado seguir el valor indicado por las escales penales.

(c) Tercero, como menciona Alonso, Roxin hace referencia al hecho de que, aparentemente, ciertas conductas son penalmente impunes no debido a que no lesionen un bien jurídico penal o a que la modalidad no sea lo suficientemente grave como para justificar una intervención penal, sino a que, muchas veces, a pesar de esto, existen remedios jurídicos alternativos a la pena. En este sentido, la falta de punibilidad o la punibilidad menos intensa de cierta conducta pueden estar basadas no en su relación con la importancia del bien jurídico o la modalidad de ataque a la que ha sido sometido, sino a otra cosa. Siguiendo este razonamiento, Alonso deja deslizar que la menor intensidad de pena del delito de OPC podría deberse no al menor valor del bien jurídico "fe pública" o que la modalidad de ataque sea en este caso menos peligrosa, sino a que el legislador cuenta a estos efectos con más alternativas para proteger el bien jurídico de las que cuenta para resguardar el patrimonio de los acreedores en el delito de QF.

Esto también es posible, pero aquí, otra vez, hubiera sido deseable que Alonso tratara de justificar cómo es que esto puede predicarse del caso en discusión, tratando de señalar cómo la OPC tiene aquí una pena de 1 a 4 años en razón de que no es necesario que tenga una pena más elevada, porque contamos con medios alternativos que, por lo menos en algún sentido, sirven para solucionar estos problemas, cosa que al no suceder con la clase de afectación del patrimonio que afecta la QF hace a esta merecedora de una pena más grave.

consecuencias penales de una acción, pero siempre dentro de la escala penal y no más allá de ella. Cfr. al respecto, Peralta, Dogmática del hecho punible, principio de igualdad y justificación de segmentos de pena, en Doxa, Cuadernos de Filosofía del Derecho, Alicante, 2008, pp. 599 ss., 614 ss. 
Pero aún concediendo este punto, esto no parece desvirtuar la función de las escalas penales. Al contrario, parece fundamentarla. Si la pena más grave para el delito de QF se debe a que aquí no hay otro remedio que recurrir al Derecho penal (o que el recurso al Derecho penal es aquí más necesario) a diferencia de la OPC donde se pueden encontrar soluciones alternativas en algunos casos, entonces las escalas penales continúan teniendo una función motivadora. Justamente debido a la falta de medios alternativos es que es más necesario proteger penalmente a los acreedores a través de la desestimulación más intensa de estas conductas. El sujeto debe, entonces, aún teniendo en cuenta estos factores, omitir pagar el cheque.

(d) Si se está de acuerdo con lo dicho hasta aquí, el pago del cheque se encuentra amparado por una causa de justificación. El bien jurídico más importante, el más lesionado o el que necesita más protección debe prevalecer sobre el otro, y la lesión a la norma que protege a este último se encuentra justificada de acuerdo a este "balance de intereses". Aquí se obra en cumplimiento del deber prevaleciente ${ }^{13}$.

Aquí se puede plantear el problema del error. ¿Qué sucede si el sujeto cree que tiene el deber de pagar el cheque? Pues bien, este sería un error de prohibición, pues el autor sabe perfectamente lo que está haciendo (no hay error de tipo en ningún sentido), pero cree que es obligatorio. Este error excluye la culpabilidad, según la doctrina mayoritaria, cuando es inevitable. Caso contrario, cuando es evitable, la disminuye y le corresponde una pena atenuada dentro de la escala penal del delito doloso ${ }^{14}$. Aquí no se plantean mayores dificultades.

\section{ACERCA DE LA "INDOMINABILIDAD NORMATIVA" DEL HECHO}

(a) Alonso descarta la solución ofrecida supra. Según sus propias palabras, "no es posible determinar qué deber jurídico prevalece

\footnotetext{
${ }^{13}$ No es para mí clara cuál es la diferencia entre un conflicto de deberes y un estado de necesidad no facultativo, en el que no se sabe qué corresponde hacer. Parece, pues, que una situación que podría caracterizarse como de estado de necesidad se transforma en un deber cuando es obligatorio actuar. Se menciona algo al respecto en el punto 4 de este trabajo.

${ }^{14}$ La evitabilidad o inevitabilidad en este caso, dependerá, normalmente, del asesoramiento legal brindado.
} 
y cuál cede". Es decir, cuál es el deber superior. De esto él concluye que, haga lo que haga, "no hay forma de sostener que el agente será pasible de sanción penal". Por ello, éste "nunca actuará antijurídicamente". "En definitiva, haga lo que haga (esto es, pague o no pague el cheque) no puede ser objeto de sanción penal por ausencia de antijuridicidad." 15

La primera dificultad surge aquí de la ambigüedad en el uso de la proposición "ausencia de antijuridicidad"16. Existen al menos dos razones para que una acción sea considerada conforme a derecho (i.e. no antijurídica). La primera, que es válida sólo para la antijuridicidad exclusivamente penal, es la falta de tipicidad de la conducta. Cuando alguien realiza una acción atípica, realiza algo que no es penalmente antijurídico (aunque pueda serlo conforme a otras ramas del ordenamiento jurídico). La segunda razón, es la presencia de causas de justificación. Cuando una acción es típica, pero está justificada, entonces esta conducta tampoco es antijurídica (y aquí también se puede hablar de que no lo sea sólo en sentido penal, aunque lo siga siendo para otras áreas del Derecho, conforme a una doctrina que viene ganando adeptos) $)^{17}$.

A pesar de esta indeterminación, se puede suponer que Alonso hace referencia al segundo supuesto (i.e. que existe aquí una causa de justificación), pues en una parte del texto rechaza, con la doctrina mayoritaria, que la solución a este problema pueda encontrarse en el tipo ${ }^{18} \mathrm{y}$, además, porque se basa expresamente en Roxin, quien considera al conflicto de deberes como un caso de "justificación supralegal"19. Esto, al mismo tiempo, suena plausible. Parece extraño afirmar que la conducta ya realizada pueda ser atípica cuando se subsume,

\footnotetext{
15 5.3., paréntesis del original.

${ }^{16}$ La misma ambigüedad se encuentra en Jakobs (n.9) 15/6.

${ }^{17}$ Hoy se encuentra cada vez más extendida la idea de que no sólo la tipicidad es específicamente penal, sino que también pueden serlo algunas causas de justificación, de tal modo que la justificación de un hecho desde el punto de vista penal no implica su justificación desde la perspectiva de otros ámbitos del ordenamiento jurídico. Cfr. Günther, Strafrechtswidrigkeit und Strafrechtsausschluss, Heymann, Köln (entre otras), 1983, passim. Para un análisis escueto del tema Roxin (n.1), nms 14/2, 14/32 ss. y 16/111 ss.

185.3 .

${ }^{19}$ Roxin (n.1), nm. 16/107.
} 
indudablemente, en uno de los dos tipos penales en pugna, y asimismo parece plausible pensar que está justificada, porque también evita la subsunción en alguno de los tipos penales. Estas últimas afirmaciones, no obstante, también esconden una ambigüedad, cuya elucidación quizás sirva para precisar un poco más la cuestión.

(b) Las causas de justificación cumplen la función general de derogar $^{20}$ el mandato señalado en el tipo. Dadas ciertas circunstancias, lo que se encuentra generalmente prohibido ya no debe ser evitado. Por supuesto, existe un interés estatal importante en que este mensaje llegue a los ciudadanos para que estos, dadas las circunstancias establecidas en la justificación, sepan cómo deben o tienen permitido actuar. En este sentido, "no se puede negar que los preceptos permisivos también están destinados a motivar comportamientos" 21 . En el caso de las causas de justificación que contienen un deber, esto es claro. Aquí se ordena realizar cierta acción. Pero la situación en los casos de simples permisiones no es distinta, pues con ella se le quiere indicar al potencial autor que el deber que establecía el tipo, dadas ciertas circunstancias, ya no rige.

La derogación del tipo en ambas clases de preceptos justificatorios tiene, entonces, la misma razón de ser: eliminar el mandato del tipo. El estado de cosas descrito por ellos ya no contiene un disvalor social que deba ser evitado penalmente. Esta función general derogatoria del precepto permisivo supone que una de las dos normas tiene vigencia sobre la otra. Es decir, que una es la que rige el caso dadas ciertas particularidades $^{22}$. Y esto vale también para la tipicidad conglobante de Zaffaroni/Alagia/Slokar ${ }^{23}$.

En efecto, Zaffaroni/Alagia/Slokar entienden que no se puede considerar típica una conducta que prima facie se subsume en una

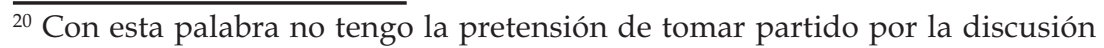
sobre la relación entre normas regla y norma excepción, por lo que la expresión "derogar" no deber ser entendida en este sentido. Cfr. al respecto, Ortiz de Urbina, (n.22) pássim.

${ }^{21}$ Sancinetti, Teoría del delito y disvalor de acción, Hammurabi, Buenos Aires, 2005, p. 536.

${ }^{22} \mathrm{Cfr}$. sobre la razón práctica por la que debe predominar la norma especial en Ortiz de Urbina, De moscas y agresores muertos, Indret Penal, Barcelona, 2008, pp.18s.

${ }^{23}$ Aunque tanto él como Roxin y Alonso luego digan otra cosa. 
norma, si hay otra que la contradice. Aquí también se entiende que una norma ha desplazado la existencia de la otra. Conforme estos autores, será atípica la conducta de dañar una cosa si, luego de un análisis "conglobante", se determina que otra norma es la que prevalece en esas circunstancias, por ejemplo, porque dicha rotura estaba implicada en el cumplimiento de un deber ${ }^{24}$. Este sería el caso del bombero que, para rescatar a un accidentado, necesita romper la ventana de una casa ${ }^{25}$.

(c) En ambas construcciones, entonces, la solución es la misma $\mathrm{y}$, en ambas construcciones, la solución es única. Del conflicto entre dos normas, se sigue que una de ellas es la que rige el caso específico. Ante la presencia de una causa de justificación, incluso en aquellas que establecen meras permisiones, rige la norma justificatoria. Así, en la legítima defensa ya no rige la norma que prohíbe matar (aunque el sujeto tenga permitido no evitar su muerte), sino que rige la norma de permisión que le quita vigencia a la anterior. Y esto no vale a la inversa. No es correcto sostener que la norma que prohíbe matar le quita vigencia a la norma que permite matar. De otro modo la norma permisiva no tendría vigencia.

Lo mismo vale, como es evidente, también para las normas que obligan a hacer algo distinto de lo señalado en el tipo. Un bombero no se encuentra, dadas las circunstancias $\mathrm{X}$, ante la alternativa de dos

${ }^{24}$ Zaffaroni/Alagia/Slokar, Derecho Penal, Parte General, Ediar, Buenos Aires, 2002, p. 496.

${ }^{25}$ En verdad, Zaffaroni/Alagia/Slokar no sacan ninguna consecuencia con relevancia práctica de la distinción entre atipicidad conglobante (por esta razón) y justificación. Esto sólo podría ser importante para la teoría del error, en la medida en que el desconocimiento de un elemento conglobante podría conducir a consecuencias distintas de las del desconocimiento de las circunstancias que justifican una conducta. El primer caso podría conducir a la atipicidad de la conducta, mientras que el segundo, a la ausencia de culpabilidad (cfr. Sancinetti (n.21) p. 526 n. 28. Claro está, para quien defienda la "teoría estricta de la culpabilidad"). Sin embargo, Zaffaroni/Alagia/Slokar no sacan esta conclusión, sino que sostienen que el error sobre los elementos que niegan la tipicidad conglobante del hecho sólo puede excluir la culpabilidad (Cfr. referencias en Sancinetti (n.21) p. 526 n. 28). Actualmente Zaffaroni/Alagia/Slokar (n.24) p. 534. Es decir, tiene las mismas consecuencias que el error sobre una circunstancia justificatoria. (Al margen, la teoría estricta de la culpabilidad ya no es defendida hoy en Alemania prácticamente por nadie). 
normas válidas, una que prohíbe el daño y la violación de domicilio y otra que afirma que es obligatorio dañar y violar el domicilio (porque este es el único medio disponible para salvar una vida). Ante esta aparente contradicción normativa el bombero sólo tiene una opción válida: cumplir con la obligación. De tal modo que si sigue la norma que señala "prohibido dañar e invadir domicilios ajenos" estará realizando algo prohibido e incluso punible. Esto no resulta modificado porque se lo analice desde la perspectiva de la tipicidad conglobante. Allí también existe una norma válida y no dos. El caso del bombero sólo será atípico si cumple con su deber ${ }^{26}$. Esto es claramente lo que sucede en el caso de un sujeto que, al ver un vehículo accidentado, se encuentra ante las alternativas de o bien romper el vidrio, y realizar el tipo del delito de daño, y rescatar a la víctima o bien no romper el vidrio y no rescatar a la víctima, y realizar el tipo de omisión de auxilio. Ambas alternativas parecen implicar el quebrantamiento de una norma y ambas conductas implican el cumplimiento de una norma de modo tal que no existe una tercera posibilidad. Pero está claro que sólo una norma es la que rige y que de no cumplirse acarrea responsabilidad penal.

Lo llamativo es que, no obstante esta unidireccionalidad de las normas de justificación, tanto Alonso como Zaffaroni/Alagia/Slokar y Roxin creen poder solucionar el problema de la contradicción normativa en base a una causa de justificación ${ }^{27}$. Y esto sin duda resulta paradójico. Lo que se está sosteniendo es, pues, lo siguiente: dada la situación $\mathrm{S}$ rige la norma N1 que deroga la norma N2 y al mismo tiempo dada la misma situación $\mathrm{S}$ rige la norma $\mathrm{N} 2$ que deroga la norma N1. Pero esto es inconcebible. Si N1 deroga a N2 entonces ya N2 no puede derogar N1, y viceversa. Dos normas no pueden derogarse simultáneamente mutuamente, porque para que una norma $\mathrm{N} 1$ derogue una norma $\mathrm{N} 2$ es necesario que tenga vigencia, es decir, que la norma N2 no derogue, al mismo tiempo, la norma N1.

(d) No obstante esto, se debe reconocer que parece plausible afirmar que ambas conductas son típicas y que ambas conductas están justificadas. Haga lo que haga el sujeto, su conducta se podrá considerar subsumida en la norma que no cumple, y por ello será típica, y haga lo

${ }^{26}$ Zaffaroni/Alagia/Slokar (n.24), pp. 496 s.

27 Zaffaroni/Alagia/Slokar, claro está, la denominan causa de atipicidad. 
que haga el sujeto su conducta podrá ser subsumida en la norma que cumple, y por ello estará justificada. Sin embargo, esto no puede ser sostenido si uno, como Alonso, distingue nítidamente entre norma primaria (o de sanción) de norma secundaria (o de conducta). En efecto, sólo puede considerarse a la conducta típica y justificada desde la perspectiva de la norma primaria, pero no desde la norma secundaria, o por lo menos no lícitamente.

La diferencia de análisis entre estas concepciones de norma se basa, justamente, en que la norma secundaria queda determinada recién una vez que ambas normas primarias se consideran conjuntamente. Como se mencionara, para el bombero existe una sola norma: obligatorio dañar e introducirse en el domicilio si esto es necesario para salvar una vida. Más allá de que para el juez o el analista de la norma de sanción se esté ante dos normas, una que prohíbe y otra que obliga la misma conducta, para quien debe obrar en base a ellas hay (y debe haber) un solo mensaje (y debe ser claro) ${ }^{28}$.

$\mathrm{Si}$ se concede que es lógicamente imposible que las dos normas se deroguen mutuamente $y$, además, que no se puede determinar cuál norma deroga a cuál, entonces no se puede establecer cuándo el sujeto obra "en cumplimiento de un deber". No pueden estar las dos justificadas y no se sabe siquiera si una de ellas lo está. La consecuencia de esto no puede ser, evidentemente, que ambas sean conductas típicas sin justificación. La misma razón que impide determinar qué conducta es la debida impide determinar cuál es la indebida, esto es, cuál es la conducta típica. La permisión y la prohibición, para la norma secundaria o de conducta, son interdependientes, porque de la conjunción de ambas normas primarias surge recién la norma secundaria. Sólo si se sabe que prevalece la norma N1 sobre la norma N2 se sabe que el sujeto debe realizar la conducta $\mathrm{C}$ y que la conducta $-\mathrm{C}$ estaba prohibida. Pero como esto es lo que no se sabe, tampoco se sabe si el sujeto debe realizar C ó -C con lo que es imposible determinar la conducta típica. En otras palabras: si no se puede establecer qué norma prevalece no se puede

${ }^{28}$ Cfr. al respecto Ortiz de Urbina (n.22), p.23: “desde el punto de vista normológico, desde el principio y hasta el final hay dos normas, mientras que desde el punto de vista pragmático el sujeto recibe un único mensaje normativo". 
determinar el tipo penal (ni el de prohibición ni el de obligación) en el sentido de la norma secundaria ${ }^{29}$.

En virtud del principio de legalidad, de lo dicho hasta aquí debe concluirse que haga lo que haga el sujeto su conducta será atípica, i.e. no regulada por el derecho en sentido fuerte. En efecto, cuando el principio de legalidad exige claridad en la descripción de los tipos penales no está pensando, en primer término, en facilitarle la labor al juez para que este pueda determinar con claridad cuándo castigar. Antes bien, tiene en mente facilitarle al individuo el acceso a la norma ${ }^{30}$. Es éste quien debe poder realizar, incluso por razones meramente prudenciales, un cálculo previsible de las consecuencias penales de sus acciones. Él es quien debe encontrarse en condiciones de prever qué hará el estado ante distintas hipótesis de conducta, porque él es quien necesita estar librado de su arbitrariedad. En este sentido, que los tipos sean precisos significa que envíen un mensaje claro al destinatario de la norma de secundaria. Y un tipo penal será claro cuando, conforme a un cierto conjunto de normas relevantes para el caso, se pueda establecer certeramente qué es lo que se debe hacer. Aquí no es posible saber qué está prohibido porque no se sabe qué está permitido y no se sabe lo que está permitido porque no se puede determinar lo que está prohibido. Debido a que estas normas son interdependientes y que no se puede determinar cuál predomina es que no hay respuesta unívoca posible y se viola el principio de legalidad en el sentido de lex certa.

Así, como afirma Roxin, en la cita del propio Alonso: "El ordenamiento jurídico sólo puede desaprobar jurídicamente y calificar como incorrecta una conducta, si puede decir qué es correcto y por tanto qué se hubiera "debido hacer""31. Pero de esto no se sigue que ambas conductas están justificadas, sino que ambas deben considerarse atípicas.

\footnotetext{
${ }^{29}$ Evidentemente, cómo debe ser calificada deónticamente una conducta no puede depender de su realización. Así, no es concebible que la conducta C sea obligatoria si se la realiza y prohibida si no se la realiza. Más aún en el derecho penal donde, para la doctrina mayoritaria, la norma está destinada a influir sobre el sujeto para determinar su comportamiento. ¿Cómo se podría enviar un mensaje si es necesario esperar a que el sujeto actúe para establecer qué debía hacer?

${ }^{30}$ Por todos Roxin, (n.1), nm.5/1 ss.

${ }^{31}$ Roxin (n.1) pp. 726/727, nm. 16/104.
} 
(e) Sobre esto, sólo una pequeña observación más. El conflicto planteado, de aceptarse la idea de que no se puede determinar cómo se debe actuar, es una contradicción normativa. Como se sabe, de una contradicción se puede seguir cualquier $\operatorname{cosa}^{32}$ y esto es lo que torna imprevisible para el sujeto evaluar las consecuencias de sus acciones. A consecuencia de ello, se puede decir que aquí no existe una regulación positiva del problema (en el sentido de que se haya previsto expresamente tener por permitido ese caso), sino sólo una negativa, derivada de la regla de clausura que rige en el Derecho penal, según la cual todo lo que no está prohibido está permitido (sin que se pueda determinar certeramente qué es lo que se está permitiendo) ${ }^{33}$. A efectos prácticos, la solución es la misma, sólo que la razón para considerarla permitida es distinta ${ }^{34}$.

Debido a esta distinción también resulta necesario diferenciar dos clases de conflicto de deberes con consecuencias jurídicas distintas. El caso de Alonso plantea un conflicto entre normas contradictorias, de modo tal que el cumplimiento de una de ellas implica la imposibilidad de cumplimiento de la otra y el no cumplimento de alguna de ellas implica el cumplimiento de la otra. Esto es lo que sucede cuando se establece simultáneamente un deber de acción y uno de omisión ${ }^{35}$. En el caso de que una norma de conducta ordene ambas, será inválida por violar el principio de lex certa.

${ }^{32}$ Alchourrón/Bulygin, Introducción a la metodología de las ciencias jurídicas y sociales, Astrea, Buenos Aires, 1998, p. 101.

${ }^{33}$ Alchourrón/Bulygin (n.32), p. 191.

${ }^{34}$ Cfr. sobre la ausencia de relevancia entre una conducta atípica y una típica pero justificada, en Ortiz de Urbina (n.22), pássim.

${ }^{35}$ Que entre una acción y una omisión siempre se deba cumplir el deber de omitir (así Roxin, n.1, nm. 16/101) sólo puede ser sostenido cuando el bien jurídico es de la misma envergadura. Pero cuando el deber de omisión es de mucho menor rango que el de acción la regla perfectamente puede invertirse. Esto es lo que sucede con quien rompe el vidrio del auto para rescatar a quien se encuentra preso dentro de éste (más allá del consentimiento presunto del dueño del vehículo, que pueda querer o consentir esta acción). Pero incluso frente a bienes de igual envergadura -excluida quizás la vida-, la regla sólo vale mientras no se tenga posición de garante $y$ no se esté ante un estado de necesidad defensivo de los bienes de un tercero. El padre que al ver a su hijo atacado por un agente sin capacidad de culpabilidad tiene derecho a herir a este para librar a su hijo del mismo daño. 
Pero existe otro conflicto de deberes que correlaciona dos normas que son sólo contrarias entre sí, i.e. que no se pueden cumplir ambas a la vez, pero que sí se pueden incumplir ambas a la vez. Esto sucede cuando las normas correlacionan dos acciones incompatibles ${ }^{36}$. Es el caso de quien ve a dos sujetos ahogándose y sólo puede rescatar a uno de ellos. En este supuesto se puede afirmar, sin contradicciones, que el sujeto tiene prohibido omitir una conducta y que, a la vez, tiene permitido también omitir una conducta. El destinatario de la norma que regula la situación conflictiva sólo puede realizar una de esas conductas (no ambas a la vez), pero está a la vez también obligado a realizar una de ellas. Debido a esto se puede concluir que tiene permitido omitir una de las dos conductas en cuestión (la alternativa a la realizada). Con otras palabras, en el caso de conflicto entre dos acciones, el sujeto no puede omitir cumplir con ambas, pero sí con alguna de ellas. Si omite cumplir ambas, entonces será sancionado por la norma que le ordenaba actuar ${ }^{37}$. Pero, en el caso de conflicto entre dos acciones, si el sujeto decide cumplir con una de ellas, la elección de qué conducta realizar -si estamos realmente ante un conflicto de deberes- es libre, no está regulada por el derecho ${ }^{38}$. En este sentido, está tan permitido que elija cualquiera de ambas conductas como, en el caso nuestro (de tener razón Alonso en que no se puede saber qué deber prevalece), que elija pagar o no pagar el cheque.

\section{SANCIÓN BAJO LAS DOS ALTERNATIVAS: LA RESPONSABILIDAD SEGÚN LAS REGLAS DE LA ACTIO ILLICITA IN CAUSA}

(a) Además de las dos soluciones mencionadas, la primera que sostiene que sólo se debe castigar en uno de los casos y la segunda que sostiene que no se debe castigar en ninguno, se puede pensar en una tercera posibilidad según la cual se debe sancionar en ambos supuestos. Para que eso sea posible, sin embargo, es necesario agregar un dato empírico que Alonso no menciona: la existencia de un peligro serio de

\footnotetext{
${ }^{36} \mathrm{El}$ conflicto entre dos omisiones es conceptualmente imposible.

${ }^{37}$ Stratenwerth (n.9), nm. 9/123.

${ }^{38}$ Jakobs (n. 9) nm. 15/6, n.11, habla aquí de "ámbito libre del derecho". 
que el librador del cheque sea declarado en quiebra antes de ser intimado al pago. Configurado este supuesto, el sujeto puede ser hecho responsable ya por la situación conflictiva en la que se encuentra y, en virtud de ello, ser sancionado luego haga lo que haga. La mejor manera de analizar esto es estudiar las reglas de la actio illicita in causa en estado de necesidad, cuya vinculación con el conflicto de deberes es patente ${ }^{39}$.

El código penal argentino justifica las conductas dañinas que se realicen para evitar un mal mayor e inminente no eludible de otro modo. Esta exención de responsabilidad no rige incondicionalmente, sino que está limitada a los casos en que el sujeto es "extraño" a la situación de necesidad (art. 34 inc. $3 \mathrm{CP}$ ). Si se entiende que con esta norma se establece una causa de justificación, de esto se sigue que en los casos en que el agente no sea extraño a la situación su conducta no podrá considerarse justificada. Lo que corresponde analizar ahora, brevemente, es, en primer lugar, el significado de la palabra "extraño" en este contexto y, en segundo, cuáles son las consecuencias jurídicas de no serlo. Ambas cuestiones se encuentran discutidas, aunque sobre ambas existen casos claros que permitirán señalar lo relevante para analizar esta posible solución.

Es extraño a la situación de necesidad a quien ésta no puede serle imputada de ningún modo. Esto es, cuando la situación ha sido generada por caso fortuito o por un tercero ajeno a los titulares de los bienes en juego. Quien resulta herido en un desastre natural o en un robo es extraño al estado de necesidad que lo coloca en la situación de tener que elegir entre su vida o el respeto del uso exclusivo de un vehículo (que puede llevarlo al hospital más cercano) por parte de un tercero.

Según la doctrina mayoritaria no es extraño a la situación de necesidad quien se coloca en ella con la intención de causar un daño a un tercero y luego quedar amparado en una causa de justificación ${ }^{40}$. Por ejemplo, un sujeto "A" que, con la finalidad de hacerle daño a "B", azuza al feroz perro de este último para verse en la obligación de matarlo

\footnotetext{
${ }^{39}$ Cfr. lo dicho en n.13.

${ }^{40}$ Robinson, Causing the Conditions of One's Own Defense, en "Virginia Law Review", vol. 71, num. 1, 1985, 1.
} 
en estado de necesidad defensivo ${ }^{41}$. Supongamos que se dan todos los requisitos del estado de necesidad, en el sentido de que el mal mayor es inminente y no eludible (ya) de otro modo. Aquí, de cualquier manera, debe negarse la mentada causa de justificación, porque la situación le es imputable al sujeto ${ }^{42}$.

En la doctrina se discuten dos posibilidades más para analizar el carácter de imputable (= no extraño) de la situación de necesidad: i. aquella en la que el sujeto ha generado la situación con dolo eventual, y ii. aquella en la que la ha generado con imprudencia ${ }^{43}$. La imputación al sujeto por la situación, en general, se debería ir atenuando en la medida en que se van superando cada uno de estos niveles. La situación de necesidad generada con dolo eventual le resulta menos imputable al autor que la generada con dolo directo (de lesión del bien de un tercero) y, a su vez, es más imputable que la generada por mera imprudencia. No corresponde aquí realizar un análisis más detenido de estas cuestiones ${ }^{44}$, sino más bien evaluar las consecuencias que de ellas se siguen, si es que es correcta esta graduación.

En particular, corresponde aquí analizar la posibilidad de desdoblamiento entre la norma primaria (o de sanción) que ordena castigar y la norma secundaria (o de conducta) que ordena actuar. En efecto, si bien se puede admitir con cierta plausibilidad que el sujeto será sancionado, en el caso, si mata al perro que él mismo ha irritado, no lo está del todo que deba tolerar el ataque del animal, es decir, que no pueda emprender una acción destinada a defenderse. Si se concluyera que, en efecto, el sujeto puede realizar la acción defensiva, se presentaría la siguiente paradoja: estaría penado (en el sentido de la norma de

${ }^{41}$ Ejemplo de Schönke/Schröder/Lenckner, Strafgesetzbuch, Kommentar, 27ma. ed., C.H.Beck, Múnich, 2006, 23/antes del 32.

${ }^{42}$ Roxin, (n.1) nm. 16/52.

${ }^{43}$ En rigor, también se analiza una tercera posibilidad, aquella en la que se ha generado la situación de peligro sobre un bien jurídico sin que se viera como previsible la posterior necesidad de lesionar el bien de un tercero. Robinson, (n.40), 16 y 20.

${ }^{44}$ En particular, sostengo que no hay ninguna diferencia entre el obrar con dolo directo y el obrar con dolo eventual, por lo que entre estas dos hipótesis no debería hacerse diferencia alguna. Pero no resulta necesario analizar aquí un tema tan intrincado. Respecto del concepto de dolo como conocimiento, Sancinetti (n.21), pp. 146 ss. 
sanción) aquello que el sujeto tiene derecho a hacer (en el sentido de la norma de conducta). La relevancia de esta distinción se divisa cuando se analiza si el dueño del perro puede ejercer legítima defensa para evitar el daño del animal. Si la acción está permitida, existe el deber de tolerar $^{45}$; si, en cambio, se trata de una agresión ilegítima, el dueño del animal tiene el derecho de evitar la acción del agente, por lo que este último debería dejarse lastimar por el perro. Y aquí parece ser que estamos en presencia de ambas cosas, pues parece una agresión ilegítima, desde que dicha acción está amenazada con pena, pero también parece un estado de necesidad justificante en el sentido de que parece contraintuitivo pensar en que ante tal desproporción de bienes se deba optar por el "mal mayor".

Existen dos formas de negar esta paradoja. La primera consiste en redefinir el concepto de mal. Si dentro de este concepto se introduce la responsabilidad del agente por el conflicto se puede obtener una solución satisfactoria que niegue el desdoblamiento mencionado. En efecto como sostenía antiguamente Binding ${ }^{46}$ e insinúa actualmente Jakobs ${ }^{47}$ la gravedad del mal se debe reducir en la medida en que el autor es imputable por él ${ }^{48}$. En el ejemplo en cuestión, puesto que el autor es absolutamente responsable del ataque del perro, no reside ningún mal jurídicamente relevante (o es un mal menor) en que este lo ataque y, por ende, no existe dilema alguno. El sujeto debe abstenerse de afectar derechos de terceros ${ }^{49}$.

La segunda solución posible consiste en adelantar el ámbito de aplicación de la norma. Se podría decir que es típico del delito de

\footnotetext{
${ }^{45}$ Roxin (n.1), nm. 15/14.

${ }^{46}$ Citado por Roxin (n.1), nm. 16/50.

${ }^{47}$ Jakobs (n.9), 13/27 y 21/84.

${ }^{48}$ En contra Roxin (n.1), 16/50. Lo cual resulta por lo demás extraño, porque Roxin acepta que si esta actividad es emprendida con intención desaparece el derecho de necesidad (cfr. aquí n.42). Con ello reconoce que la actividad del agente puede, por lo menos en algunos casos, reducir el valor del bien jurídico. Claro que se puede pensar que sin intención, i.e. con dolo eventual, no pierden tanto su valor. Pero esto puede ser tenido perfectamente en cuenta en la mensuración de la pena. Ver, además, lo que sigue en este texto.

${ }^{49}$ Así es de hecho como en la legítima defensa se habla de que el mal de matar al agresor es menor que el del homicidio de este. La razón radica en la responsabilidad del agresor por el conflicto. Cfr. Sancinetti (n.21), p. 519 s.
} 
daño ya emprender una acción en la que el autor se coloque ante dos alternativas en donde el mal menor ( $\sin$ incluir ahora su responsabilidad) implique la comisión del delito mencionado. Allí se encuentran fundamentadas ambas normas, la de sanción y la de conducta, de tal modo que no existe aquí tampoco desdoblamiento $\operatorname{alguno}^{50}$. Se le anuncia al autor una pena en el caso de que se decida a emprender una acción con este tipo de consecuencias y ante esa acción se podría pensar una legítima defensa del tercero que sabe que sólo a costa de sus bienes se podrá evitar el mal mayor.

Aquí se puede objetar una violación al principio de legalidad en cuanto a que la conducta de, supongamos, levantar un palo frente al perro no se subsume en la norma que prohíbe el daño ${ }^{51}$. Tampoco parece claro que, como sostiene Roxin ${ }^{52}$, se pueda afirmar aquí siquiera una tentativa. Es cierto que se ha generado un riesgo equivalente al que se quiere censurar con el tipo que castiga la tentativa (el riesgo de no poder evitar un daño) y que, por ende, ya se configuran aquí los presupuestos que legitiman el castigo en base a esa figura, pero es difícil que el principio de legalidad permita entender como "comienzo de ejecución" del delito de daño la incitación a un perro a atacar. Sin embargo, para esto existe en el Derecho argentino una solución sencilla. La norma que dice que el sujeto no debe ser extraño a la situación generada está ampliando ya por ley el ámbito de interpretación de la norma. En otras palabras, sería una interpretación auténtica del alcance de los tipos penales particulares en estas circunstancias concretas. Si esta ley tiene la precisión suficiente para satisfacer el sentido de lex certa es otra pregunta.

De aceptarse esta interpretación, la reconstrucción final sería la siguiente. Cuando el sujeto comienza la ejecución de su acción de provocación al perro comienza la tentativa. Esta queda acabada ya cuando pierde el dominio sobre la reacción del animal (cuando el azuzamiento fue "suficiente"). A partir de este momento lo que sigue

\footnotetext{
50 Schönke/Schröder, (n.41), loc. cit.

${ }^{51}$ Roxin, (n.1) nm. 16/54 y, en atención al mismo problema en la a.l.i.c. 20/61.

${ }^{52}$ Roxin, (n.1) nm. 20/61, en relación a la a.l.i.c. y en 20/65 en la a.i.i.c. en el estado de necesidad exculpante.
} 
es todo resultado ${ }^{53}$. Todo el daño que el sujeto se ve forzado a realizar para evitar el ataque del perro es la consumación de un ilícito que había empezado antes y cuya posibilidad de evitación había perdido ya al perder el dominio sobre el perro.

(b) La segunda solución (adelantar el ámbito de vigencia de la norma) resulta más satisfactoria que la primera (redefinir el concepto de daño), en primer lugar, porque resulta más intuitiva. A un "montañero" que ha emprendido "una escalada" parece sensato permitirle "que penetre en una cabaña privada para no congelarse" y al suicida que "se tira al agua" y luego "cambia de opinión" parece demasiado prohibirle el uso de la barca de un tercero si desea salvarse ${ }^{54}$. Pero, justamente porque sus acciones implican estos riesgos para terceros se les podría impedir que emprendan dichas actividades, no ya con argumentos paternalistas sino liberales. En estos supuestos, cuando el sujeto pierde el control de las circunstancias que generan el peligro (no puede bajar de la montaña o no puede volver a la orilla) ha culminado la tentativa y lo demás es un resultado ya "inevitable".

Pero la segunda razón por la que privilegiar esta solución se basa en su coherencia con casos análogos. Así, y ya acercándonos más a nuestro problema, esta segunda solución es satisfactoria para los casos en que el agente pone en conflicto dos acciones igualmente desagradables, pero cuya dañosidad recae en ambos supuestos sobre bienes jurídicos ajenos. Un ejemplo es el siguiente: "A" quiere destruir la granja de "B". Para esto comienza un fuego en la zona rural que pone en riesgo de incendio extensiones de campo inmensas, con el consiguiente peligro para viviendas y vidas de varias personas. La única forma de evitar que el fuego de propague, como lo sabía "A" antes de efectuar la conducta mencionada, es realizar un "contrafuego" para lo que necesita quemar la granja de "B" $\mathrm{B}$.

Aquí no se puede plantear la posibilidad de que "A" no neutralice el peligro inicial. No sólo por la superioridad de los daños en juego, sino porque además "A" no puede consentir sobre bienes jurídicos

\footnotetext{
${ }^{53}$ En el mismo sentido Schönke/Schröder/Lenckner, (n.41), loc. cit.

${ }^{54}$ Este y otros ejemplos en Roxin, (n.1), 16/51; en el mismo sentido de lo dicho en el texto, Robinson, (n.40), 28; Schönke/Schröder/Lenckner, (n. 41), loc. cit. ${ }^{55}$ Ejemplo de Robinson, (n.40), 3 s.
} 
ajenos. La posibilidad de permitir legítima defensa por parte del dueño de la granja sólo es imaginable, si acaso, ante el caso de que el propio "A" se haya colocando intencionalmente entre la alternativa de sus bienes o su vida o la granja de "B". Pero de ningún modo puede admitirse esto si lo que está en juego son los bienes y la vida de terceros. Aquí, indudablemente, existe el deber de salvar el bien de mayor preponderancia para cuya mensuración de ningún modo puede incluirse la responsabilidad del agente (no titular del bien jurídico) por el conflicto $^{56}$.

En este caso, el sujeto no es extraño a la situación y, por ende, no puede ampararse en el estado de necesidad para ser eximido de pena. Pero también está fuera de discusión que la única alternativa posible es la de elegir el mal menor, si es el único medio disponible para evitar el mal mayor inminente. Para dar cuenta de esto coherentemente lo que se debe entender es que lo que está prohibido, y sobre lo que cabe legítima defensa por parte del tercero ajeno al conflicto, es que se emprenda la actividad que va degenerar en el conflicto mentado. Con el emprendimiento de la primera acción el sujeto ya se ha hecho responsable, en el ejemplo dado, por el delito de daño y su situación sólo puede empeorar si es que no realiza la acción de salvamento. Con otras palabras, el sujeto ya ha hecho todo para ser responsable del incendio de la granja del vecino (i.e. ha acabado la tentativa) y sólo la suerte podría mejorar su situación (evitar el resultado). La omisión de esa conducta, por el contrario, lo transformaría en autor del delito de incendio doloso ${ }^{57}$.

\footnotetext{
${ }^{56}$ Con el consiguiente deber de la policía de evitar el mal menor dando lugar al mal mayor.

${ }^{57}$ Esto es valorativamente idéntico a la situación de quien imprudentemente lesiona a un transeúnte con el auto en un lugar en el que este no puede recibir asistencia de terceros. Ya el hecho de haberlo lesionado lo hace responsable de todas las consecuencias de sus actos que ni con la mejor de las voluntades pueda evitarse. Así, si inmediatamente lo conduce al hospital, pero esto no puede evitar que las lesiones sean graves, esas lesiones le serán imputables. Por el contrario, si lo deja allí ya con esa conducta (si se dan el resto de los requisitos -i.e. falta de posibilidad de asistencia de terceros, posibilidad de que las lesiones, ante la falta de asistencia desencadenen un resultado mortal-) comete una tentativa de homicidio y si luego muere será responsable por
} 
La estructura de análisis que se utiliza para solucionar estos casos se denomina actio illicita in causa, que es similar a la de la actio libera in causa con la diferencia de que aquí no se puede obrar de modo lícito debido a la falta de culpabilidad, mientras que allí lo es a causa de que ninguna de las acciones disponibles puede considerarse lícita ${ }^{58}$. En ambos casos, la responsabilidad surge de una conducta anterior punible y como en la a.l.i.c también en la a.i.i.c. la responsabilidad por el acto posterior debe basarse en el grado de imputación del sujeto por el riesgo. Si lo hizo con intención ${ }^{59}$, deberá responder por su conducta posterior por dolo directo. Si, en cambio, sólo conocía, pero no deseaba que ocurriera, su responsabilidad posterior será por dolo eventual y así sucesivamente $^{60}$. En rigor, ambas estructuras responden a la responsabilidad por injerencia y son ambas una cuestión perteneciente a la estructura de la imputación objetiva.

Con este esquema de análisis en mente puede verse que son infundadas las objeciones en cuanto a que, con esta comprensión, se llega a soluciones contradictoras que, además, son políticocriminalmente inconvenientes ${ }^{61}$. La contradicción entre permitir y sancionar, como se ha visto, es sólo aparente en la medida en que lo sancionado y prohibido es emprender la acción generadora del riesgo ${ }^{62}$. En cuanto su inadecuación político-criminal, Roxin afirma que "si el autor ha de pensar que es cierto que va a estar justificado al emprender el salvamento por esa acción salvadora, pero que va a ser castigado por

homicidio. Todas las lesiones que surjan del hecho inicial y sean inevitables le serán imputadas si es que hace todo lo que pueda para que la situación no sea aún peor. En este sentido, su omisión sólo puede empeorar su situación.

${ }^{58}$ Existen también diferencias prácticas, por ejemplo, en la oportunidad para ejercer la legítima defensa. Mientras que en la a.i.i.c., cuando se pone en juego bienes de terceros, la legítima defensa sólo es posible en el momento de emprender la acción riesgosa y luego existe el deber de tolerar, en la a.l.i.c. la legítima defensa puede ejercerse hasta último momento.

${ }^{59}$ Cfr. n.44.

${ }^{60}$ Por todos Jakobs (n.9), $21 / 84$.

${ }^{61}$ Así, no obstante, Roxin (n.1), 16/54; en similar sentido Robinson, (n.40), 27.

${ }^{62}$ En igual sentido Jakobs, (n.9), 21/84, quien habla aquí de un hecho justificado en autoría inmediata, pero injustificado en autoría mediata; también Robinson, (n.40), 27 ss., pero sin hacer referencia alguna a la relevancia del resultado. 
su conducta previa, la mayoría de las veces se abstendrá de realizar la acción salvadora para no incurrir en responsabilidad penal" ${ }^{13}$. Lo que aquí olvida Roxin es que si el sujeto se abstiene de actuar será responsable por los daños que ocurran de no emprender la acción salvadora ${ }^{64} \mathrm{y}$, por ello, deberá optar por una u otra acción teniendo en consideración cuál es la que impone menos pena ${ }^{65}$, entre otras cosas ${ }^{66}$.

(c) A esta altura se debe analizar si la estructura aquí desarrollada de modo esquemático se puede utilizar en el caso de marras. La situación planteada por Alonso tiene en común con el estado de necesidad que el sujeto se encuentra ante dos alternativas aparentemente antijurídicas y punibles. Además, aquí, como los casos discutidos supra en (b) de este punto, se encuentran en juego bienes jurídicos ajenos, i.e. no de exclusivo interés del sujeto actuante. Y en ambos casos los titulares de los bienes jurídicos carecen de responsabilidad por la situación conflictiva. Si la respuesta fuera positiva, y se pudiera usar este esquema, la norma aplicable a este caso no sería: "está prohibido estar intimado al pago de un cheque rechazado sin fondos estando sujeto a las reglas concursales" ${ }^{67}$, sino "está prohibido emprender una conducta que implique el riesgo de colocarse ante dos acciones incompatibles e igualmente típicas" ${ }^{\prime 6}$. Estaría prohibido librar el cheque si existe el riesgo de que al deber pagarlo se tenga que realizar un ilícito penal.

\footnotetext{
${ }^{63}$ Roxin, (n.1), 16/54.

${ }^{64}$ Robinson, (n.40), 28.

${ }^{65}$ Esto es, por lo menos, lo más conveniente para el autor del hecho. Por eso es importante la coherencia entre pena y riesgo a evitar. En el caso de bienes de igual envergadura, al estar amenazados ambos con la misma pena, las dos acciones serán igual de desestimulantes, con lo que el argumento de Roxin se anula por sí mismo.

${ }^{66} \mathrm{Cfr}$. punto 2 del presente texto.

675.1 .

${ }^{68}$ Se puede pensar una relación entre esta conducta y la de estafa. En efecto, quien libra un cheque sabiendo que no podrá pagarlo está induciendo en error a la contraparte. Y este error puede generar una disposición patrimonial perjudicial. En este supuesto se podría pensar un concurso ideal entre estafa y libramiento de cheque que luego no podrá ser legalmente pagado. Pero, de todos modos, la coincidencia será contingente. La estafa tiene más requisitos que el delito de libramiento de cheques que aquí se analiza. El libramiento del cheques no requiere disposición patrimonial en contra alguna. Ya sea porque la contraprestación se iba a efectuar después del cobro (donde el sujeto haya
} 
Para eso, lo primero que cabe preguntarse es si el libramiento del cheque envolvía un riesgo considerable de que su librador fuera declarado en quiebra antes de la intimación al pago de dicho documento. Dadas estas circunstancias, el libramiento del cheque configura la creación de un riesgo no permitido de colocarse en la situación conflictiva (de la que sólo se podrá salir violando alguno de los dos deberes). En segundo lugar, se debe evaluar si el librador conocía las implicancias de su conducta, esto es, si el riesgo no permitido generado le puede ser imputado subjetivamente ${ }^{69}$. Para quien defienda que una situación conflictiva sólo puede ser atribuida si el agente obra con dolo directo, habrá que evaluar si, además de conocer el riesgo, tenía la intención de perjudicar a alguna de las partes. La responsabilidad por imprudencia queda descartada, porque ninguno de los dos delitos en cuestión está previsto de ese modo ${ }^{70}$.

Establecido el caso así con estos datos adicionales, como último punto corresponde evaluar si las reglas de la actio illicita in causa, le pueden ser aplicadas al conflicto de deberes. Como una cuestión valorativa, quien la admita para el estado de necesidad, en principio, no tiene ninguna razón para negarla para el conflicto de deberes $^{71}$. Pero mientras nuestro $\mathrm{CP}$ da cuenta de esta regla para el estado de necesidad al exigir el carácter de "extraño" del agente para hacer

obrado asumiendo el riesgo de no poder pagar el cheque y ver así frustrada su operación comercial) o porque no se iba a configurar nunca: el caso de una donación de dinero. $Y$, en todo caso, sólo podrá ser válida en la medida en que el autor opte por no pagar el cheque. Si lo hace y defrauda a la masa de la quiebra, tampoco podrá hablarse de estafa (más allá de que haya sido pagado al margen de la ley). La relación entre estafa y esta propuesta de solución fue sugerida por Andrés Bouzat en oportunidad de la presentación del texto de Alonso en la Universidad Nacional del Sur, Bahía Blanca, en noviembre de 2008.

${ }^{69}$ Roxin, (n.1), 16/52.

${ }^{70} \mathrm{Y}$ esto con independencia de que la conducta final sea, evidentemente, dolosa. Por eso se habla de actio illicita in causa. Lo importante es el estado mental del agente al emprender la acción. Cfr. Mir Puig, (Derecho penal, parte general, 5ta ed., Reppertor, Barcelona, 1998, nms. 17/79 s., aunque usa una terminología inadecuada.

${ }^{71} \mathrm{Y}$ en la legítima defensa con el requisito, universalmente admitido, de "falta de provocación suficiente". Cfr. sobre la relación entre conflicto de deberes y estado de necesidad lo dicho en n.13. 
operativa la justificante, no sucede lo mismo cuando existe un conflicto de deberes. La aplicación de esta regla en este caso constituiría, entonces, probablemente, una analogía in malam parte.

Pero quizás no sea necesario conformarse con la afirmación de que estamos ante una laguna axiológica ("sería justo que el sujeto sea sancionado haga lo que haga, pero debemos conformarnos con la solución expuesta aquí en 2. o en 3."). El art. 302 del CP, en su inciso segundo, prevé expresamente esta posibilidad, para el caso de libramiento de cheque, al tipificar que será sancionado "el que dé en pago o entregue, por cualquier concepto a un tercero un cheque, a sabiendas de que al tiempo de su presentación no podrá ser legalmente pagado"72. La doctrina afirma al respecto que este supuesto se configura cuando las "circunstancias ... colocan al librador en situaciones jurídicas particulares que no permiten afrontar el pago del cheque (librador que está en quiebra o concursado cuando libra el cheque...)."73 Pero, asimismo, se afirma que no es necesario que el impedimento sea preexistente al libramiento del cheque, sino que alcanza con que sea cierto que aparecerá en el futuro. Creus/Buompadre dan el ejemplo de "quien sabiendo que está en camino la comunicación al banco girado del embargo de todos los fondos de la cuenta, libra el cheque en otra plaza minutos antes de que se reciba allá esa comunicación"74. Con un poco de imaginación no es difícil subsumir nuestro caso en este tipo penal. Si el librador del cheque sabía de un modo certero que prontamente sería declarado en quiebra (v. gr., porque ya se había iniciado judicialmente el trámite al respecto y estaban dadas todas las condiciones para que esto fuera resuelto por el tribunal en breve, o porque ya existía una sentencia no firme al respecto) sabía también que era muy probable que el cheque no fuera (legalmente) pagado a su presentación y, en consecuencia, su conducta podría subsumirse perfectamente en esta norma. (Por supuesto, para que esta solución sea

\footnotetext{
${ }^{72}$ Nótese que el texto sólo parece requerir dolo eventual al usar la expresión "a sabiendas".

${ }^{73}$ Creus/Buompadre, Derecho penal, Parte especial, 7ma. ed., Astrea, Buenos Aires, 2007, p. 555; en el mismo sentido Soler, Derecho penal argentino, t.5, 3ra. ed., Tea, Buenos Aires, 1970, p. 389 s.; Fontán Balestra/Ledesma, Derecho penal, Parte especial, 16ta. ed., Lexis-Nexis, Buenos Aries, 2002, 1014 s.

${ }^{74}$ Creus/Buompadre (n.73), p. 555.
} 
operativa hay que sostener que la respuesta brindada en 2. es la correcta. De otro modo, no tendría imposibilidad legal alguna de pagar el cheque.)

\section{RESUMEN}

El artículo de Alonso ha servido para un debate que excede, por su contenido, los comentarios aquí reproducidos. Me he limitado a realizar observaciones desde la dogmática penal y ellas reflejan, creo, un esfuerzo para aportar algo a la discusión. He dividido mi aporte en tres partes, dos de ellas netamente críticas y una tercera que constituye más bien la sugerencia de análisis.

En primer lugar, he defendido que existe una respuesta que diluye el conflicto de normas en caso de conflicto entre QF y OPC, porque de hecho existe un solo deber debido a que una norma prevalece sobre la otra. Para saber qué mandato se debe seguir, en este supuesto, sólo es necesario detenerse en las escalas penales establecidas para cada alternativa de conducta. Aquella que establece la pena más elevada es la que determina la opción no aprobada por el Derecho. Es cierto que las escalas penales sólo tienen la primera palabra para solucionar un conflicto entre deberes. Sin embargo, muchos de los argumentos esgrimidos para dejarlas de lado, más bien parecen fundamentar su valor decisorio que debilitarlo. Una interpretación sofisticada de las afirmaciones de Alonso para que estas sí puedan poner en jaque el valor prima facie de las escalas penales, requería, de todos modos, de datos adicionales para dejar de lado ese valor indiciario, datos que no fueron proveídos Alonso y, en verdad, no parece que existan.

En segundo lugar, analicé, de modo independiente, la solución defendida de Alonso. Sostuve allí que aunque las escalas penales no pudieran dirimir el conflicto, la propuesta de Alonso es incorrecta. Calificar a ambas conductas como permitidas en virtud de que sendas normas que las regulan sancionan la conducta opuesta, sólo aparentemente es una solución. No es conceptualmente posible que ambas normas rijan simultáneamente y si, como sostiene Alonso, ningún procedimiento puede determinar cuál predomina, entonces estamos ante una verdadera contradicción normativa de la que se puede seguir 
cualquier cosa. Debido a esto y a que el principio de legalidad requiere, principalmente, que los destinatarios de las normas reciban un mensaje claro, es que corresponde afirmar aquí la falta de tipicidad de la conducta, i.e. que no hay norma válida que, en verdad, regule qué se debe hacer en este supuesto.

Finalmente, he propuesto una tercera solución agregando datos que no están en el caso presentado. Esta sostiene que puede estar justificado que el sujeto deba ser sancionado en los dos supuestos, pague o no el cheque. Para que una sanción semejante pueda considerarse legítima (desde el punto de vista de la moralidad del castigo estatal) es necesario recurrir a un momento en el que el sujeto haya generado, evitablemente, un riesgo jurídicamente desaprobado. La justificación, entonces, del castigo en los dos supuestos, sólo puede encontrarse en una conducta anterior realizada por el sujeto que generara un riesgo considerable de encontrarse posteriormente en la situación de conflicto de deberes. Y, de hecho, esto es lo que parece estar previsto en el inc. 2 del art 302 del CP, que, dadas las condiciones, sería de aplicación al caso. Por supuesto, siempre es necesario que ese riesgo pueda serle imputado también subjetivamente al autor. 